nihilism, Skrabanek and McCormick demand constant critical vigilance and radical scrutiny of the taken-for-granted. Are we not losing our sense of proportion if we assume the yard-stick of medical progress is the prolongation of life at all costs? May not quality of life, freedom from anxiety and individual liberty count for more? It is fashionable to scare people into health with campaigns against cholesterol and the promotion of regular checkups; but exposing people to half-baked diets and additional doctoring may be just as harmful.

Occasionally, Skrabanek and McCormick hoist themselves on their own petard, when their debunking passion evidently learned from Martin Gardner gets the better of their own critical faculties. They assert, sweepingly, that "the present activities of surgeons general, health education councils, and many

\section{Hominid whodunnit}

\section{G. Ainsworth Harrison}

Piltdown. A Scientific Forgery. By Frank Spencer. Oxford University Press: 1990. Pp. 272. £17.95, \$24.95.

The Piltdown Papers. By Frank Spencer. Oxford University Press: 1990. Pp. 282. £30, $\$ 65$.

THE fascination of the Piltdown forgery is apparently endless. It was indeed one of the most gigantic frauds in scientific history: it bedevilled understanding of the fossil record of human evolution and went unexposed for more than forty years. Perhaps the continuing fascination comes from the fact that the circumstances of the perpetration of the fraud remain obscure, and the guilty party or parties not unequivocally identified. Whether one can get nearer to the truth eighty years on than J. S. Weiner's exposure of the fraud in 1953 is rather doubtful, but nonetheless Spencer's book is a scholarly and important contribution to the now enormous literature dealing with the Piltdown forgery.

The nature of the original finds, which were apparently extracted from the lower Pleistocene gravels near Uckfield in Sussex, in the United Kingdom, between 1912 and 1915, are well known: the finds consisted of substantial parts of a human cranium which was essentially modern; much of a mandibular horizontal ramus which was very ape-like; a canine-tooth which fitted perfectly the prediction of Sir Arthur Smith Woodward; sufficient of a second individual to show that one was not dealing with a fortuitous association; and some artefacts and fossil mammals. All turned out to have been 'salted', and the academic departments of public health and the like, are in danger of corrupting medicine by morality". Maybe, but, by their own criteria, we're at least entitled to some evidence of this. All the reader gets, however, is an anecdote from Manila and a quotation from Plato: hardly proof positive of a point whose rhetoric is rousing but which actually requires serious evaluation.

Yet Follies and Fallacies never expects to be the last word. Fired especially at medical students, it aims to provoke more than to prove. And in this it succeeds, and leaves one looking forward to a further training of the Skrabanek and McCormick artillery against hypocrisies and halftruths.

Roy Porter is at the Wellcome Institute for the History of Medicine, 183 Euston Road, London NW1 2BN, UK.

jaw and teeth 'doctored' to show some human characters

Subsequent fossil discoveries, particularly in Africa, made Piltdown ever more anomalous. Human evolution proceeded by modification of the jaws before substantial change in the size of the brain, rather than the other way round. Nonetheless, authors of books on palaeoanthropology in the 1940s still gave a central place to Piltdown, often identifying it with the ancestry of modern man. In such schemes, other fossils were all side branches. That such a position could be sustained for so long is remarkable - at least with hindsight! It was not helped by the fact that almost everyone working on
Piltdown had to work with caste material. But eventually Weiner recognized what a nonsense it was, proposed the forgery explanation, demonstrated in collaboration with K.P. Oakley and Sir Wilfrid Le Gros Clark the scientific basis to the fraud and undertook his own investigation into the perpetrators. He concluded in his book The Piltdown Forgery (1955) that Charles Dawson, a local solicitor, amateur naturalist and the 'discoverer' of the first finds, almost certainly had to be heavily involved; but whether he was alone or had accomplices was not completely clear. On balance, Weiner favoured Dawson's sole involvement.

Since then many others have tried their detective skills, and fingers have been pointed at almost every possible figure associated with the finds or with Dawson. It seems that one only needed to have purchased potassium dichromate (which was used to 'fossilize' the bones) around 1912 to have come under suspicion. Strangely, perhaps, one of the few people to escape accusation has been Sir Arthur Keith, then conservator of the Hunterian Museum of the Royal College of Surgeons, who devoted much of his life to researching Piltdown, particularly the reconstruction of the cranium from the fragments recovered. That omission is corrected in Spencer's book, in which the proposition is developed that Keith was Dawson's scientific accomplice and perhaps instigator of the whole affair.

Keith's involvement was first seriously suggested by Ian Langham, a young Australian historian and anthropologist who died tragically in 1984. Langham's work

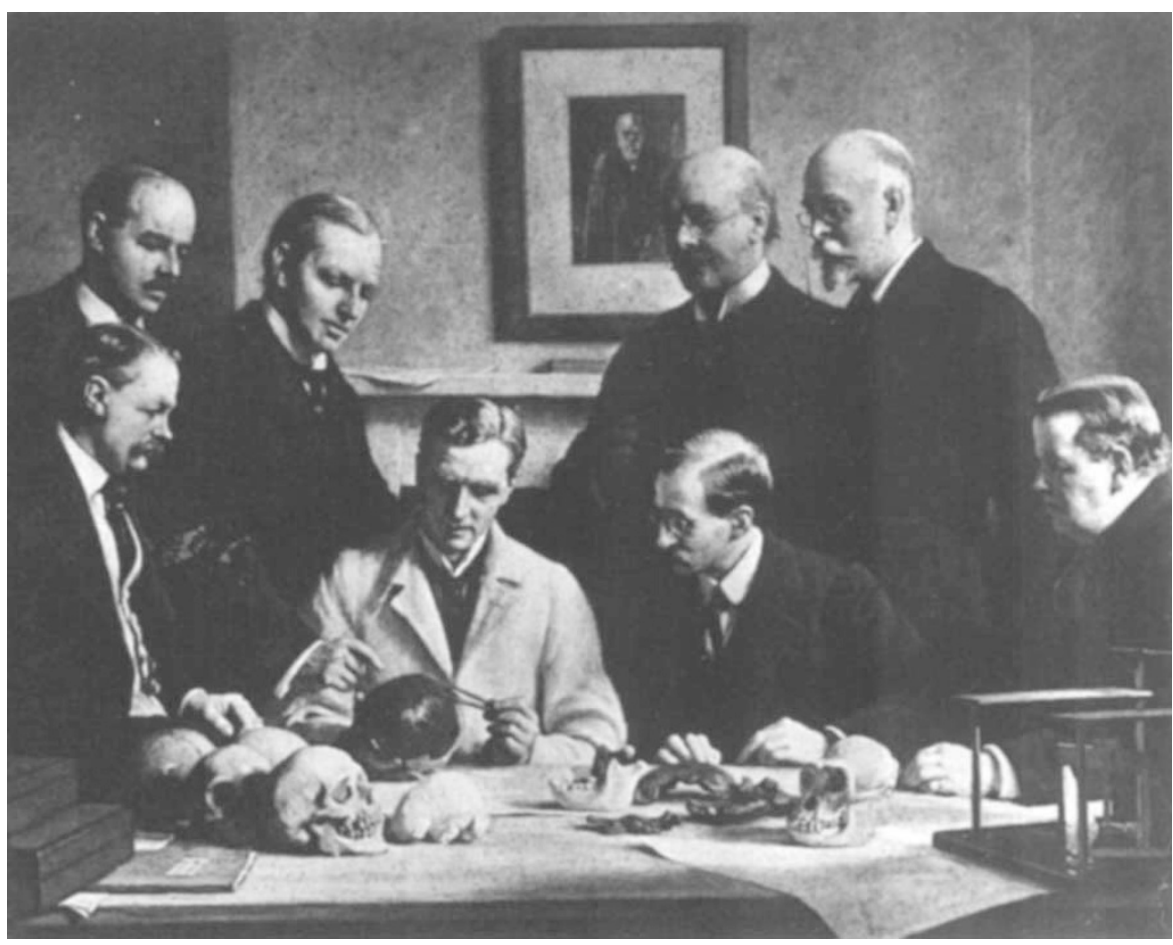

The 'Piltdown gang' as painted by John Cooke - Arthur Keith is seated (centre) wearing a labcoat, Charles Dawson and Arthur Smith Woodward are standing (left and right, respectively) to the right of the painting. 
was passed by his family to Spencer to develop and publish. Spencer has not only done this but also set it within the whole Piltdown saga. He clearly shares the same verdict of guilt as Langham. But their case is not only circumstantial, as it is almost bound to be, but also, in my opinion, very thin. It largely rests on Keith apparently knowing a little more about the circumstances of the find than might initially have been expected - and some of this assertion depends on a judgement of what might have been conveyed in an hour's conversation between Smith-Woodward and Keith. There is also a suggestion that Dawson and Keith may have known each other rather better around the time of the discoveries than they publicly acknowledged.

I have to say I am quite unconvinced by this evidence. I am, however, privileged to know J. S. Weiner's views on Keith's reaction to the fraud's exposure. I was in effect acting as a research assistant to Weiner at this time, and accompanied him on many occasions during his investigation. Unfortunately, I was not present when he interviewed Keith, but I remember his account the following day. He said that Keith appeared utterly taken aback and dismayed by the idea that Piltdown

\section{Integrity on trial}

\section{Ralph A. Lewin}

Where The Truth Lies. By Jan Sapp. Cambridge University Press: 1990 . Pp.340. Hbk £30, \$59.50; pbk £15, \$18.95.

JAN Sapp has reviewed the life and times of Franz Moewus, and discussed implications of his scientific publications. If you have heard of Moewus (1908-59) you will certainly want to read Sapp's review; if you have not, I urge you to do so anyway. The Moewus saga (a saga is a story, not always completely truthful) is wider in scope, in time and in moral implications than those of Piltdown Man or Kammerer's black-toed toads. Was his work a tissue woven largely of lies, or a set of insightful if irreproducible experiments? Was Moewus a fraud or a prophet, or a bit of both? He was certainly bright - but then, an embezzler has to be bright if he is to succeed in beating the system.

The Moewus story began in Germany, interluded in Australia, and ended in the United States. Most of his publications dealt with a hitherto obscure little alga, Chlamydomonas, but they had implications for our understanding of microbial sexuality, physiology, biochemistry and genetics. Indeed, in 1940 many considered that Moewus' work was at the forefront of microbial biochemical genetics (if not was fraudulent. He had no doubt at all that Keith was not involved.

In the second edition of The Antiquity of Man published in 1925, Keith devotes 248 out of 734 pages to Piltdown. By this time he had received a knighthood and was a Fellow of the Royal Society. Would he by then have spent so much time and effort and identified himself so closely with something that he knew was false? Why did he have so much difficulty reconstructing the cranium if he had been party to the construction of the fake? For me the accusation just does not ring true. I do, however, applaud Spencer's book as a whole, which is well researched and attractively written. With the accompanying volume of collected papers and letters it provides the definitive history of Piltdown: the 'discovery', the exposure and the long search for the culprit. Spencer also documents not only how damaging this fraud was to science, but also to the reputations of those who were unfortunate enough to be in any way associated with it.

G. Ainsworth Harrison is in the Department of Biological Anthropology, University of Oxford, 58 Banbury Road, Oxford OX2 6QS, UK.

actually of molecular biology, which I think started somewhat later). He was backed by powerful scientific figures: $\mathrm{M}$. Hartmann and R. Kuhn in Germany, and later Sonneborn in the United States, although almost everything he reported was at best irreproducible, and at worst downright fishy. His final scientific demise (as Sapp puts it) was in a dénouement at the Marine Biological Laboratory, Woods Hole in 1954.

Should he be dismissed simply as a charlatan? Sapp, a science historian and philosopher, thinks not, for at least two reasons. Moewus, he contends, saw the light and pointed the way to microbial genetics as soon as, if not sooner than, the Nobel laureates G. Beadle, E. Tatum and $\mathrm{J}$. Lederberg. If he fabricated or fiddled his data - and there is irrefutable evidence for this - his peccadillos could be partly cxcused by the political and social systems in which he worked. All scientists do a little fiddling, Sapp avers; indeed, some fiddling is almost expected of all of us, and in Nazi Germany this was more true than elsewhere.

I have read Sapp's book twice, and I cannot fully agree with his premises. He reiterates that there is more truth in fiction than in fact - but is there? Most scientists I know plod along, year by year, grant by grant, finding out little items about the nature of things and reporting them reasonably objectively (that is, truthfully). Few of us (I can certainly speak for us biologists) espouse doctrines so enthusiastically that we adjust our data to fit them. (Admittedly there was the nasty aberration of lysenkoism, but surely that was a historic exception.) Few of us belong to specific schools of dogmatic thought, as Sapp would have us believe, publishing our results as adversarian treatises, as protagonists of this doctrine or antagonists of that. (This may be true among clergymen, philosophers, and perhaps to lesser degrees among linguists or economists, but not us biologists.) If Sapp had been a scientist himself, I think he would have agreed with me. But he is not, and he argues forcefully and repetitiously that truth is mostly in the mind of the scientist, as is beauty in the eye of the beholder.

Sapp has done an extensive piece of archival research. This book deals with some 70 publications by Moewus and some 40 more by his coauthors, his reviewers and his detractors. (Certain relevant publications by $\mathrm{L}$. Wiese, $\mathrm{K}$. Thimann and M. Hagen-Seyffert have received less attention than they merit in this connection.) It is also based on extensive interviews with various people who knew Moewus and who have ideas about his publications - including Mrs Kobb, Moewus' widow - and on almost 90 items of correspondence and other peripheral literature. (A contemporary and compatriot of Moewus' to whom I showed Kobb's paragraphs dismissed much of her pleading as "pathetic nonsense", and suggested that Sapp might have been more critical.) Some 50 of the latter items were from the extensive files of the late T. M. Sonneborn, initially Moewus' strongest supporter in America and, later, one of his most disillusioned correspondents. Sapp has also added chapters embodying his own ideas about truth in science and the way it is elucidated, about the work of Gregor Mendel (some of whose data were also statistically questionable, though the orders of magnitude of the respective improbabilities were considerably different), and about the general origins of microbial genetics. The relevance of some of this is peripheral, but it is certainly of educational value.

1 think all kinds of scientists would profit by reading this book. But I hope it does not fall into the hands of scientifically illiterate pundits in law or politics; they might get wrong ideas about the integrity and veracity of scientists in general. After all, truth will out in the long run. If you question this, then look into the latest compilation of scientific information about Chlamydomonas, edited by Libby Harris in 1989, and see how little credence has eventually been placed in the publication of Moewus.

Ralph A. Lewin is at the Scripps Institution of Oceanography, University of California, La Jolla, California 92093, USA. 